\title{
Kinetic of Transport of Technogenic Ecotoxicants through Model Membranes
}

\author{
Elena A. Saratovskikh, Boris L. Psikha
}

Institute of Problems of Chemical Physics, Russian Academy of Sciences, Moscow, Russian.

Email:makarov@icp.ac.ru

Received January $19^{\text {th }}, 2010$; revised July $6^{\text {th }}, 2010$; accepted July $15^{\text {th }}, 2010$.

\begin{abstract}
The kinetics of ecotoxicant transport through the membrane was studied. The ecotoxicants studied were pecticides widely used in agriculture: lontrel (clopyralid), sencor (metribuzin), basagran (bentazon), roundup (glyphosate), kusagard (alloxydim sodium), and sethoxydim, as well as lontrel complexes with cobalt and copper. All compounds considered penetrate through the model phosphatidylcholine liposomal membranes. The transfer rate was monitored by fluorescence quenching of E-ATP inside the liposomes. The mathematical model for the process was proposed, and the mass transfer rates were calculated. The octanol/water partition constants were determined. All the compounds considered were shown to accumulate in the fatty layer. The kinetics of their accumulation was studied, and the rates of accumulation in the nonpolar phase were calculated, which correlate with the complexation constants of the same compounds. Bioaccumulation of the toxicants is caused by the formation of complexes with the fatty phase (lipid part) of the cellular membranes. The toxicants under study transferred into the nonpolar phase with a considerable rate during the whole observation time, namely, 18 months.
\end{abstract}

Keywords: Ecotoxicant Pesticides, Liposomal Membranes, Mass Transfer Constants, Lipophilicity, Bioaccumulation, Octanol/Water Partition $\left(\mathrm{K}_{\mathrm{oct} / \mathrm{H} 2 \mathrm{O}}\right)$

\section{Introduction}

Technogenic ecotoxicant xenobiotics (foreign substances for living cells), such as pesticides, are presently predominant contaminants of the environment $[1,2]$. They also can accumulate in biological systems at almost all trophic levels. In living organisms, the degree of bioaccumulation (ratio of the amount of the toxicant in the tested subject to that in the reference sample) can be very high. For instance, the accumulation of chloropyriphos in the Pimephales promelas fish achieves $1.7 \cdot 10^{3}$ times and that of dichlorodiphenyltrichloroethane is $1.3 \cdot 10^{5}$ times [1]. Xenobiotics accumulate mainly in the lipid part of cellular membranes by binding of the samples with membrane proteins or lipids [3]. As a result, pesticides influence on the structure and functions of the membranes and can destruct the membrane systems $[4,5]$. Among various physicochemical properties of a pesticide sample, lipophilicity exerts a determining effect on the character of interaction of the sample with the lipid bilayer. Lipophilicity is usually characterized by the octanol/water partition coefficient $\left(\mathrm{K}_{\mathrm{oct} / \mathrm{H} 2 \mathrm{O}}\right)$.
To understand the mechanism of action of xenobiotic pesticides, one should evaluate their ability to penetrate inside the cell. Therefore, it is desirable to use for studying pesticide transport through the cellular membrane such systems and conditions under which the wholeness of the membranes is retained. In most cases, model systems, viz., liposomes filled with various substances, are widely used to investigate the transport of drugs, vitamins, hormones, viruses, and antibiotics through the membranes [6]. In particular, permeability of the liposomal membranes for pesticides and other toxicants of technogenic origin were studied [7] to form concepts on hazard of microcontaminants of water for human being.

A series of our studies [8-10] revealed the role of complexation processes in the mechanism of action of xenobiotics at the molecular level. It was shown, particularly, that mono- (in particular, ATP and its derivative $\varepsilon$-ATP), di-, and polynucleotides form complexes with the pesticides, resulting in fluorescence energy loss $[8,9]$. Therefore, in the present study we used liposomes containing in the internal volume $\varepsilon$-ATP, whose fluores- 
cence quenching reflects pesticide penetration through the membrane.

The purpose of the present work is to detect and quantitatively characterize the transfer rate though the liposomal membrane for a series of pesticides: lontrel, sencor, basagran, roundup, and sethoxydim, as well as lontrel complexes with cobalt and copper, and to determine the partition constants in an octanol/water system and the rates of transfer to the nonpolar phase and accumulation in it.

\section{Methodology}

The names and chemical formulas of the used pesticides and metal complexes are given in Table 1. The substances under study were isolated from commercial samples and purified according to an earlier developed method [8]. The complexes of the herbicide lontrel with different metals were synthesized according to a known procedure [10-15]; the synthesis of E-APT was carried out by a previously proposed procedure [8]. The following commercial preparations were used without additional purification: egg phosphatidylcholine, $10 \%$ solution in ethanol (Serva, Germany), purity at least $98.5 \%$; cholesterol (analytical purity grade, Reakhim, Russia).

To determine the octanol/water partition constant $\left(\mathrm{K}_{\mathrm{oct} / \mathrm{H} 2 \mathrm{O}}\right)$, a solution of the pesticide under study $(10 \mathrm{ml}$ in the initial concentration) was poured to octyl alcohol $(10 \mathrm{ml})$. The resulting mixture was shaken for $20 \mathrm{~min}$ and left to settle. The concentrations of the studied pesticide in water and octanol were determined on a Specord UV-VIS spectrophotometer (Carl Zeiss Jena, Germany). The initial concentrations, wavelength in the absorption maximum, and molar absorption coefficients of the substances used are listed in Table 1. After the first measurement, all mixtures were poured to specially constructed sealed vessels that made it possible to take samples from the upper fatty phase (with a pipette) and lower aqueous phase (through a valve at the ground section in the bottom of the vessel). To simulate the bioaccumulation of the ecological toxicants in subjects of the environment, the pesticide concentrations in water and octanol were repeatedly measured (followed by the calculation of $\mathrm{K}_{\mathrm{oct} / \mathrm{H} 2 \mathrm{O}}$ ) in 15 days, 30 days, 3 months, 6,12 , and 18 months. The solutions were kept at room temperature between measurements.

To prepare multulayer liposomes, a mixture of phosphatidylcholine $(2 \mathrm{ml})$ and cholesterol $(0.2 \mathrm{ml})(10 \%$ solution in chloroform) was dried in an inert gas flow on a rotary evaporator (Rotavapor EL 131 and Water Bath Büchi 461, "Büchi" Switzerland). The resulting film was poured with a buffer $(2.5 \mathrm{ml}$ of $0.02 \mathrm{M}$ Tris- $\mathrm{HCl}$ buffer, $\mathrm{pH}$ 7.2) and thoroughly stirred for lipid swelling. To ob- tain monolayer liposomes, a suspension of multulayer liposomes was ultrasonicated using a described procedure [16] with a UZDN-1 ultrasonic low-frequency disperser (USSR) at $22 \mathrm{kHz}$ and $0.4 \mathrm{~A}$ for $20 \mathrm{~min}$ in the presence of $\varepsilon$-ATP (in $0.02 \mathrm{~mol} \cdot \mathrm{l}^{-1}$ Tris-HCl buffer, $\mathrm{pH}$ 7.2) during $30 \mathrm{~s}$ followed by cooling for $60 \mathrm{~s}$ at $0-5^{\circ} \mathrm{C}$ in an argon atmosphere. The free label was separated from the encapsulated label by gel filtration on columns filled with the Sephadex G-50 sorbent (Pharmacia, Sweden) controlling by a UNICOD Type4701A flow-type densimeter (LKB, Sweden). The size of the obtained liposomes $(60-100 \mathrm{~nm})$ was determined with a JEM-100B electron microscope (Japan) described earlier [16].

Etheno derivative of adenosinetriphosphoric acid with the excitation spectrum at $\lambda=312 \mathrm{~nm}$ and fluorescence maximum at $\lambda=420 \mathrm{~nm}$ was used as the fluorescent label [17]. The choice of $\varepsilon$-ATP as a label was caused by the fact that its quantum yield of fluorescence is one of the highest yields among other etheno derivatives of nucleotides, being 0.59 in the $0.025 \mathrm{~mol} \cdot \mathrm{l}^{-1}$ phosphate buffer [18] at $\mathrm{pH}$ 7.0. The concentration of $\varepsilon$-ATP inside liposomes was determined on a Specord M-40 spectrophotometer (Jena, Germany) by the band at $\lambda=275 \mathrm{~nm}$ with the molar absorption coefficient [18] $\varepsilon=6 \cdot 10^{3}$. In all experiments, the initial concentration of $\varepsilon$-ATP inside the liposomes was $10^{-4} \mathrm{~mol} \cdot \mathrm{l}^{-1}$. After the experiment, a solution of the liposomes was subjected to gel filtration on a column packed with the Sephadex G-50 sorbent, after which the concentration of free $\varepsilon$-ATP inside the liposomes was determined again.

Fluorescence was measured on an Aminco-Bowman spectrofluorimeter (USA) in a standard cell $(1 \times 1 \mathrm{~cm})$ in a liposome suspension $(2.7 \mathrm{ml})$ in the $0.02 \mathrm{~mol} \cdot \mathrm{l}^{-1}$ Tris$\mathrm{HCl}$ buffer, $\mathrm{pH}$ 7.2. In all entries, the initial fluorescence intensity $\mathrm{I}_{0}=6.5 \pm 0.5$ was determined only by the concentration of $\varepsilon$-ATP and the volume of the liposome suspension added to the working cell and remained approximately the same in all entries. Experiments were carried out by adding the pesticides to the cell with the liposome suspension to a volume of $3 \mathrm{ml}$ with the final pesticide concentrations $10^{-2}, 10^{-3}$, and $10^{-4} \mathrm{~mol} \cdot \mathrm{l}^{-1}$. The change in the fluorescence intensity was detected during 19-21 h. The fluorescence intensity changes weakly during the first 5-10 min after the pesticide was added to the cell containing a liposome solution. This fact indicates that the wholeness of the liposomal membranes was not perturbed and no $\varepsilon$-ATP molecules escaped from the liposomes to the external solution.

To be sure that the pesticides penetrate inside the liposomes and $\varepsilon$-ATP does not leak out, we carried out control measurements with the copper and cobalt complexes. In these experiments, 20-22 $\mathrm{h}$ after the beginning of measurements, the suspension of the liposomes was 
Table 1. Names, initial concentrations, absorption wavelength maxima, and chemical formulas for the compounds used.

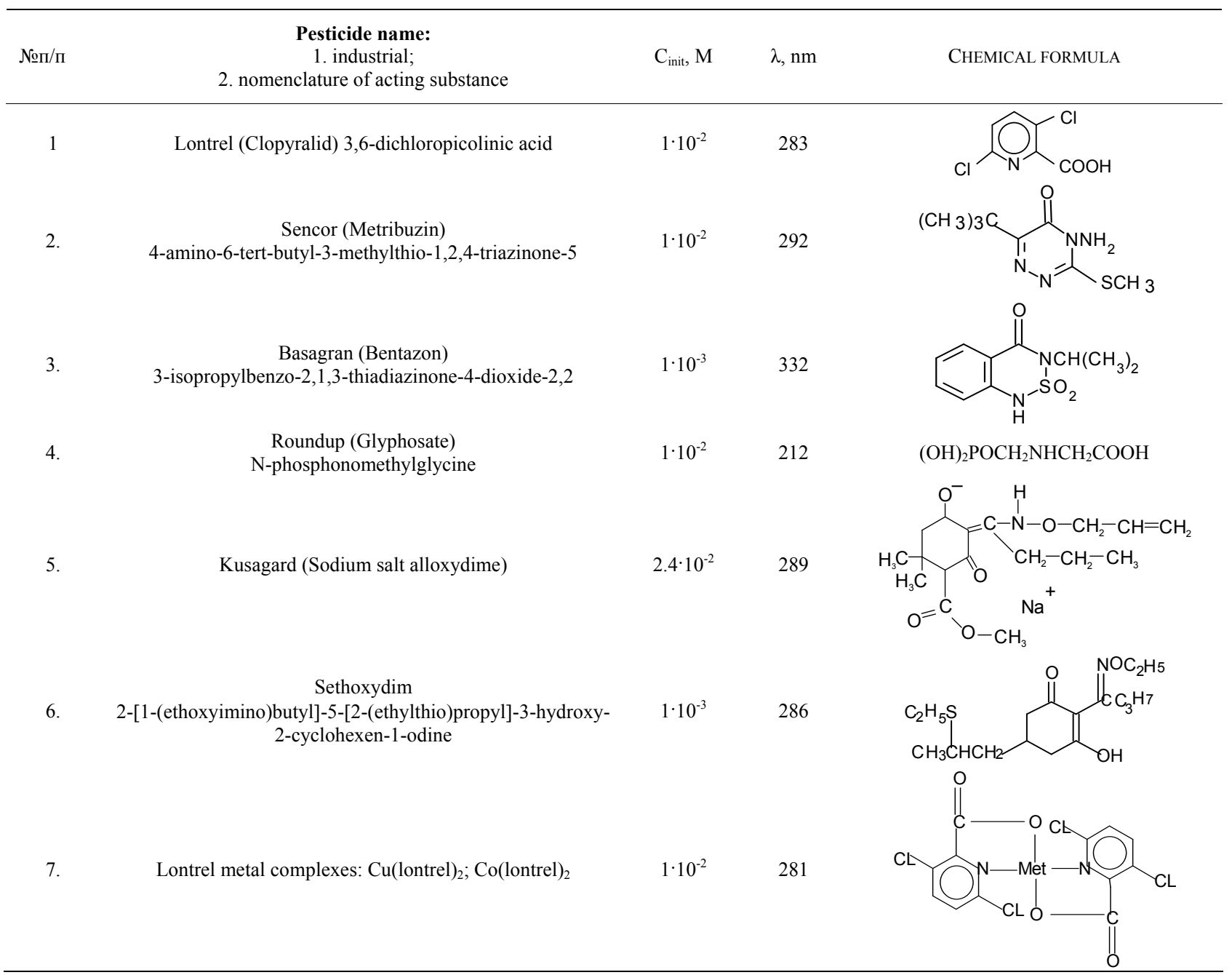

repeatedly passed through the separation column (Sephadex G-50) and elemental analysis of the separated liposome suspension was carried out to determine the content of metals (cobalt and copper).

In each series of experiments, three pesticide concentrations were used, and reproducibility of data in each entry was checked for three independently prepared samples of the liposomes.

\section{Results and Discussion}

\subsection{Determination of Wholeness of the Liposomes}

The results obtained in preliminary experiments showed that the cobalt content inside the liposomes corresponds to $\sim 5 \cdot 10^{-5} \mathrm{~mol} \cdot 1^{-1} \mathrm{Co}(\text { lontrel })_{2}$-ATP and the copper content corresponds to $\sim 6.2 \cdot 10^{-5} \mathrm{~mol} \cdot \cdot^{-1} \mathrm{Cu}(\text { lontrel })_{2}$-ATP, which agrees well with the experimental data and predictions of the model on the content of the reaction products.
Thus, it was experimentally shown for these two cases that quenching occurs directly inside the liposomes. An additional confirmation that the wholeness of the liposomes was retained was obtained in a series of experiments, when $20 \mathrm{~h}$ after the beginning of measurement of the quenching kinetics, the pesiticide was additionally added in a high concentration (their concentration in the suspension increased by 10 times). In these entries, no noticeable changes in the fluorescence intensity and its quenching rate occurred.

\subsection{Mass Transfer Rate}

The studied process consists of two stages: 1) penetration of pesticide through the liposome membrane; 2) interaction of pesticide with $\varepsilon$-ATP. Earlier it was shown by us [8] that the interaction of pesticides with $\varepsilon$-ATP occurs instantaneously and is characterized by a complexation constant $(\mathrm{Kc} /$ form). Therefore the transport of pesticide through a membrane is the limiting stage and can be 
evaluated from the $\varepsilon$-ATP fluorescence quenching rate inside liposomes. The $\varepsilon$-ATP concentration inside liposomes is not stationary during experiment, but decreases in time due to complexation of $\varepsilon$-ATP with pesticide.

The results of measurements of the relative fluorescence intensity $(I(t) / I(0))$ in time for all the substances studied at three initial pesticide concentrations are presented in Figures 1 and 2. In all entries, the $\varepsilon$-ATP fluorescence was quenched within a rather prolonged time $(20 \mathrm{~h})$ during which the fluorescence intensity decreased to $70-60 \%$ of the initial value.

We considered the following model of the studied process for the quantitative analysis of the experimental results. The pesticide molecules $(P)$ from the cell with the volume $V_{1}$ penetrate in the internal volume of the liposomes $\left(V_{2}\right)$ with the rate $j(t)$ and enter into the equilibrium reaction with the $\varepsilon$-ATP molecules $(E)$ to form product $\Pi$, which is incapable of fluorescing

$$
P+E \stackrel{K}{\longleftrightarrow} \Pi
$$

where $K$ is the equilibrium constant of the formation of product $\Pi$.

The system of kinetic equations describing the change in the reactant concentrations inside the liposomes takes the form

$$
\begin{gathered}
\frac{d([P]+[\Pi])}{d t}=j(t) \\
K \cdot[P] \cdot[E]=[\Pi] \\
{[\Pi]+[E]=E_{0}} \\
{\left[P_{1}\right] \cdot V_{1}+([P]+[\Pi]) \cdot V_{2}=P_{0} \cdot V_{0}}
\end{gathered}
$$

Here $E_{0}$ is the initial concentration of $\varepsilon$-ATP inside the liposomes, $\left[P_{1}\right]$ is the pesticide concentration in the cell outside the liposomes, and $P_{0}$ and $V_{0}$ are the concentration and volume of the pesticide solution introduced into the cell before the beginning of experiment, respectively. Equation (1) with allowance for Equations (2) and (3) can be rewritten with respect to the concentration $[E]$ in the form

$$
\frac{K \cdot[E]^{2}+E_{0}}{K \cdot[E]^{2}} \cdot \frac{d[E]}{d t}=-j(t)
$$

Since the $\varepsilon$-ATP concentration inside the liposomes [E] is related to the experimentally measured fluorescence intensity $I(t)$ through the simple relation

$$
[E]=E_{0} \cdot I(t) / I(0),
$$

Equation (5) can be used for the calculation of the transfer rate of the pesticide through the lipid membrane $j(t)$. To calculate the transport rate of the pesticide inside the liposomes, we used the earlier obtained by us [8]

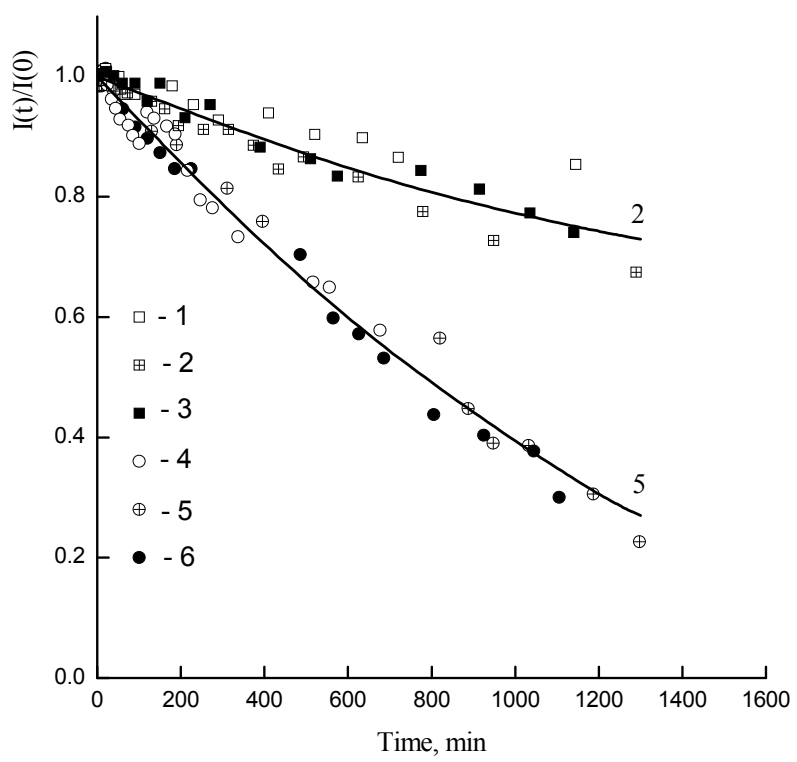

Figure 1. Change in the fluorescence intensity of \&-ATP encapsulated into the liposomes after the addition of lontrel (1-3) and Co(lontrel) $)_{2}$ complex (4-6). Concentration of E-ATP is $1 \cdot 10^{-4} \mathrm{~mol} / \mathrm{l}$. Concentration of the pesticides in the cell: $1 \cdot 10^{-4}(1,4) ; 1 \cdot 10^{-3}(2,5) ; 1 \cdot 10^{-2}(3,6) \mathrm{mol} / \mathrm{l}$. Here and in Figure 2 the initial fluorescence intensity remained approximately the same and equal to $I_{0}=6.5 \pm 0.5$. Solid lines $(2$, 5) are theoretical curves plotted by Equation (5) with the parameters given in Table 2.

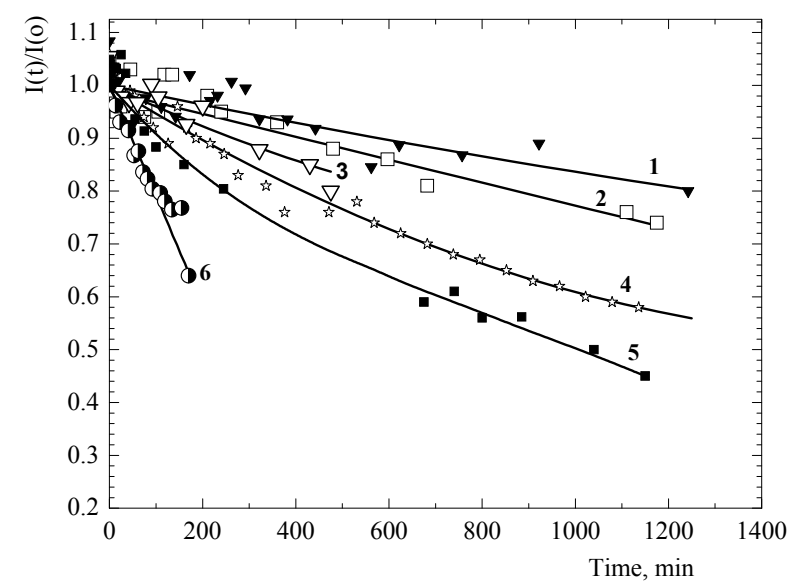

Figure 2. The same as in Figure 1, for the pesticide concentration $1 \cdot 10^{-3} \mathrm{~mol} / \mathrm{l}$. Points indicate the experimental data with various pesticides: 1 , basagran; 2 , sencor; 3 , kusagard; 4, roundup; 5, sethoxydim; 6, copper complex of lontrel herbicide $\left(\mathrm{Cu}(\mathrm{L})_{2}\right)$. Solid lines are theoretical curves plotted by Equation (5) with the parameters given in Table 2.

formation constants of the $\varepsilon$-ATP-pesticide complexes presented in Table 2.

The expression for the rate of pesticide penetration from the external volume inside the liposomes $j(t)$ depends on the mechanism of pesticide transfer through the 
Table 2. Octanol/water partition constants, mass transfer rate constants, and complexation constants of the pesticides and metal complexes.

\begin{tabular}{|c|c|c|c|c|c|c|}
\hline & \multirow{3}{*}{ Substance } & \multicolumn{3}{|c|}{ Pesticide concentration } & \multirow{3}{*}{ Average value $\mathrm{J} \cdot 10^{8}, \mathrm{M} \cdot \mathrm{s}^{-1}$} & \multirow{3}{*}{$\mathrm{K}_{\mathrm{c} / \text { form }} \cdot 10^{-3}$, with $\varepsilon$-ATP according to [7] } \\
\hline & & $10^{-2} \mathrm{M}$ & $10^{-3} \mathrm{M}$ & $10^{-4} \mathrm{M}$ & & \\
\hline & & \multicolumn{3}{|c|}{$\mathrm{J} \cdot 10^{8}, \mathrm{M} \cdot \mathrm{s}^{-1}$} & & \\
\hline 1. & sencor & 2.1 & 7.6 & 2.8 & $4.2 \pm 1.7$ & $26.5 \pm 3.3$ \\
\hline 2. & lontrel & 4.1 & 5.2 & 2.8 & $4.1 \pm 0.7$ & $15.9 \pm 2.0$ \\
\hline 3. & kusagard & 14.7 & 14.7 & 14.5 & $14.6 \pm 0.1$ & $9.7 \pm 0.5$ \\
\hline 4. & roundup & 10.9 & 13.8 & 9.7 & $11.5 \pm 1.2$ & $8.2 \pm 1.2$ \\
\hline 5. & sethoxydim & 40.5 & 41.2 & 39.6 & $40.4 \pm 0.5$ & $5.0 \pm 0.3$ \\
\hline 6. & basagran & 5.9 & 6.1 & 5.1 & $5.7 \pm 0.3$ & $4.7 \pm 0.4$ \\
\hline 7. & $\mathrm{Cu}(\text { lontrel })_{2}$ & 18.0 & 15.6 & 21.2 & $18.3 \pm 1.6$ & $851 \pm 82$ \\
\hline 8. & $\mathrm{Co}(\text { lontrel })_{2}$ & 7.0 & 6.2 & 8.0 & $7.1 \pm 0.5$ & $600 \pm 200$ \\
\hline
\end{tabular}

lipid membrane. At first we considered the most probable mechanism of simple diffusion for which the rate of pesticide transfer is proportional to the difference of its concentrations outside $\left[P_{1}\right]$ and inside $[P]$ the liposomes:

$$
j(t)=\beta \cdot\left(\left[P_{1}\right]-[P]\right)
$$

where $\beta$ is the mass transfer coefficient or membrane permeability [11]. The $\beta$ parameter quantitatively characterizes the substance transfer through the membrane, and the task was to determine the $\beta$ value from the experimentally measured dependence of the $\varepsilon$-ATP concentration $[E]_{\exp }$ on time $t$. The problem was solved as follows. In each entry, the $\beta$ value that minimizes the functional

$$
\Phi(\beta)=\sum_{i=1}^{n}\left([E]_{\exp }\left(t_{i}\right)-[E]_{\text {calc }}\left(t_{i}\right)\right)^{2}
$$

where $n$ is the number of points in the entry and $[E]_{\text {calc }}\left(t_{i}\right)$ is the $\varepsilon$-ATP concentration inside the liposomes at the time moment $t_{i}$ calculated from the system of Equations (1)-(4) at the given $\beta$ value, was determined from the experimental kinetic curve $[E]_{\text {exp }}(t)$ using a computer. It turned out, however, that the $\beta$ mass transfer coefficient value depends strongly on the initial pesticide concentration $P_{0}$ : for each pesticide in three entries at the initial pesticide concentrations $10^{-4}, 10^{-3}$, and $10^{-2} \mathrm{~mol}$ we obtained three $\beta$ values, which differed from each other by $\sim 10$ and $\sim 100$ times (inversely proportional to the initial concentrations).

This unexpected result is understandable from the formal point of view. As can be seen from the data shown in Figure 1, the experimentally observed quenching rate (and hence, the rate of pesticide penetration inside the liposomes) is virtually independent of the initial pesticide concentration. Taking into account the experi- mental error, the relative fluorescence is independent of the initial quencher concentration in entries with both lontrel (group of experimental points 1-3) and its complex with cobalt $\mathrm{Co}(\text { lontrel) })_{2}$ (group of experimental points 4-6), as well as for all other toxicants and metal complexes studied in this work. Thus, the assumption that the pesticide is transferred through the liposomal membrane via the mechanism $j(t)=\beta \cdot\left(\left[P_{1}\right]-[P]\right)$ contradicts the experimental data.

Based on the observed specific feature of the experiment and taking into account the results of calculations, we repeated experimental data processing assuming that the transfer rate of the pesticide inside the liposomes is independent of the gradient of its concentrations, accepting formally that $j(t)=\beta$, i.e., $j=$ const. The results of calculation are presented in Table 2: the $j$ values obtained at different initial concentrations of each pesticide are given in columns 4-6, and their arithmetical mean is given in column 7 . It can be seen from the data in Table 2 that the $j$ values calculated at different concentrations of each pesticide do not already depend explicitly on these concentrations. This makes it possible to average the obtained $\mathrm{j}$ values and characterize each pesticide by the average value of the transfer rate through the lipid membrane.

The theoretical quenching curves were calculated by the determined $j$ values and compared with the experimental ones. As follows from the data in Figures 1-2, the calculation performed using Formula (5) describes satisfactorily the available experimental data.

Let us analyze the data presented in Table 2. Sethoxydim and kusagard exhibited the highest rate. Both these compounds have complex structure and bear large organic fatty fragments. Roundup follows kusagard, and 
the transfer rates of basagran and lontrel are close. The series considered is closed by sencor, which is the most reactive complexing agent according to [8]. Among the considered compounds, the maximum penetrating ability was manifested by ketones, cyclohexanone derivatives, and then derivatives of arylphosphoric acid, pyridine, and triazine. The pesticides can be arranged in the following order by the mass transfer rate: sencor $<$ lontrel $<$ basagran $<$ roundup $<$ kusagard $<$ sethoxydim. The mass transfer rate of the $\mathrm{Cu}$ (lontrel $)_{2}$ complex is higher than that of $\mathrm{Co}(\text { lontrel })_{2}$.

Since the result obtained (transfer rate of the pesticides through the lipid membrane is independent of their concentration) differs from the commonly accepted concepts on the diffusion mechanism of the process, we attempted to reveal reasons for the observed phenomenon. First, we checked whether the phenomenon is related to the solubility of the studied pesticides in the fatty phase or not. For this purpose, we measured the octanol/water partition coefficients $\mathrm{K}_{\mathrm{oct} / \mathrm{H} 2 \mathrm{O}}$ (Table 3, column 3). Sencor and basagran manifest the highest ability to be dissolved in an organic solvent. This ability indirectly reflects lipophilicity of chemical compounds. According to the lipophilicity values, the pesticides studied can be arranged in the following order: sencor $>$ basagran $>$ sethoxydim $>$ lontrel $>$ roundup $>$ kusagard. As can be seen, this sequence differs from the above series for the mass transfer rate.

\subsection{Schemes of Interact with Phospholipid Molecules}

At the same time, we have shown previously that the pesticides considered can react with organic compounds to form complexes characterized by high stability constants $[8,9]$. Some relation between the transfer rates $J$ and complexation rate constants $\left(\mathrm{K}_{\mathrm{c} / \text { form }}\right)$ of the pesticides with functional structures of the living cell, viz., ATP, NADH, DNA, and RNA, is observed. This is exemplified in Table 2 by the $K_{\mathrm{c} / \text { form }}$ constants of the pesticides with $\varepsilon$-ATP. It can be seen that the compounds (except for basagran that possesses intrinsic fluorescence and the lontrel metal complexes that have their own sequence of biological activity) with high $\mathrm{K}_{\mathrm{c} / \text { form }}$ values are characterized by the low penetration rate through the cell membranes, i.e., the mass transfer rate constants have an inverse relation to the complexation constants with $\varepsilon$-ATP: their ability to form complexes [8,9]. The presence of such a relation allows us to assume that the transfer of the pesticides through the lipid membrane is not a purely diffusional process but is limited by the chemical interaction with some elements of the lipid membrane analogously to the phenomenon of negative active diffusion [12].

It was shown by NMR, ${ }^{1} \mathrm{H}$ NMR, and introduction of fluorescent labels that the pesticides are entrapped into the hydrocarbon part of the lipid bilayer. It was also assumed in several studies that the pesticide is arranged parallel to the hydrocarbon chains and thus can form a 1: 1 complex with phosphatidylcholine $[3,13,14]$.

In the case of lontrel (3,6-DCPA), whose acidity is caused by the chlorine atoms, the formation of a complex with lipids in the model liposomal or cellular membrane can occur with covalent bonding upon the elimination of water and $\mathrm{HCl}$, as shown in Scheme 1(b).

The orientation of the 3,6-DCPA molecule parallel to the phosphatidylcholine molecule is possible due to the electronegative oxygen atom of the phosphate group of lecithin and the $\mathrm{N}$ atom of the pyridine ring bearing a partial positive charge $\left(\delta^{+}\right)$, as well as due to the electrostatic interaction of the chlorine atom of 3,6-DCPA and positively charged $\mathrm{N}$ atom of phosphatidylcholine.

The chemical structure of a phosphatidylcholine molecule is shown in Scheme 1(a). The structure of a possible 3,6-DCPA complex with two phosphatidylcholine molecules is presented in Scheme 1(c).

A sencor molecule can also interact with one or two phospholipid molecules. As shown in Scheme 2(a), covalent bonds can be formed due to both the highly reactive sulfur atom and lone electron pairs of the nitrogenatom of the heterocycle. In this case, a stable five-mem-

Table 3. Octanol/water partition constants, bioaccumulation coefficients, and accumulation rates of the pesticides in octanol.

\begin{tabular}{|c|c|c|c|c|c|c|c|}
\hline $\begin{array}{c}\text { Names } \\
\text { of substances }\end{array}$ & $\begin{array}{l}\mathrm{K}_{\mathrm{oct} / \mathrm{H} 2 \mathrm{O}} \\
20 \mathrm{~min}\end{array}$ & $\begin{array}{c}\mathrm{K}_{\mathrm{oct} / \mathrm{H} 2 \mathrm{O}} \\
18 \text { months }\end{array}$ & BC & $\begin{array}{l}\mathrm{V}_{1} \cdot 10^{-3}, \mathrm{M} \cdot \mathrm{h}^{-1} \\
20 \mathrm{~min}\end{array}$ & $\begin{array}{l}\mathrm{V}_{2} \cdot 10^{-8}, \mathrm{M} \cdot \mathrm{h}^{-1} \\
6 \text { months }\end{array}$ & $\begin{array}{c}\mathrm{V}_{3} \cdot 10^{-8}, \mathrm{M} \cdot \mathrm{h}^{-1} \\
18 \text { months }\end{array}$ & $\mathrm{K}_{\mathrm{c} / \text { form }} \cdot 10^{-3}, \mathrm{M}^{-1}$ \\
\hline sencor & $66.57 \pm 2.0$ & $100.4 \pm 3.0$ & $0.99 \pm 0.01$ & 32.84 & 0.37 & 0.37 & $26.5 \pm 3.3$ \\
\hline lontrel & $2.56 \pm 0.1$ & $3.38 \pm 0.1$ & $0.77 \pm 0.03$ & 23.97 & 4.06 & 4.06 & $15.9 \pm 2.0$ \\
\hline kusagard & $0.30 \pm 0.01$ & $0.77 \pm 0.03$ & $0.44 \pm 0.01$ & 18.47 & 46.10 & 32.60 & $9.7 \pm 0.5$ \\
\hline roundup & $0.46 \pm 0.014$ & $2.27 \pm 0.07$ & $0.69 \pm 0.02$ & 10.50 & 42.67 & 18.90 & $8.2 \pm 1.2$ \\
\hline sethoxydim & $7.83 \pm 0.23$ & $25.00 \pm 0.8$ & $0.96 \pm 0.03$ & 2.96 & 0.58 & 0.58 & $5.0 \pm 0.3$ \\
\hline basagran & $52.19 \pm 1.8$ & $70.4 \pm 2.12$ & $0.99 \pm 0.01$ & 3.27 & 0.04 & 0.04 & $4.7 \pm 0.4$ \\
\hline
\end{tabular}




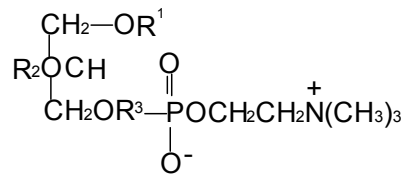

(a)<smiles>C[N+](C)(C)CCOP(C)(=O)[O-]</smiles>

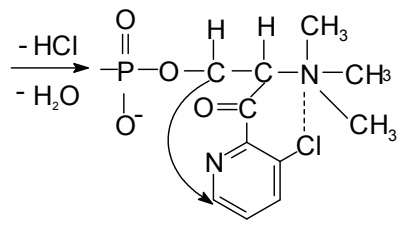

(b)

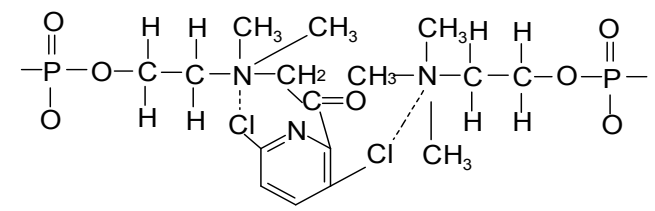

(c)

Scheme 1. Structure of a phosphatidylcholine molecule (a) and possible lontrel complexes with one (b) and two (c) phospholipid molecules.

bered ring can be formed between sencor and phospholipid.

The oxygen of the free keto group releases its lone electron pair to form the ether bond with the second phospholipid molecule, as if hanging by the ends of the fatty acids (see Scheme 2(b)). Evidently, the reactivity possibilities of the sencor molecule are not exhausted by the both types of interactions. The enhanced electron density on the nitrogen atoms of the sencor heterocycle can allow sencor to react with one more (third) or even two (third and fourth) phosphatidylcholine molecules.

The roundup molecule has three hypothetical addition sites: the terminal hydroxy groups and carboxy group, as well as the nitrogen atom localized in the middle of its linear structure. Naturally, this molecule can readily realize its possibilities reacting with one or two phosphatedylcholine molecules (Scheme 3).

The analysis of the pesticides used in the work from the viewpoint of reactive chemical substituents in their structure prone to covalent bonding with phosphatidylcholine suggests that this affinity decreases in the series: lontrel $>$ sencor $>$ lontrel metal complexes $>$ roundup $>$ kusagard $>$ sethoxydim $>$ tachigaren (hymexazol) $>$ basagran. This order agrees with the experimental data on the octanol/water partition constants and, naturally, is inversed to the order of mass transfer rates through the

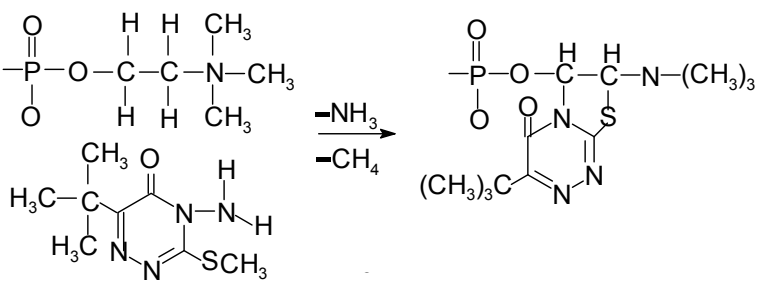

(a)<smiles>CN(C)C1C(OP(C)(=O)O)=NN=NC(C(C)(C)C)C1OC[N+](C)(C)CCOP(C)(=O)O</smiles>

(b)

Scheme 2. Scheme of possible complex formation of sencor with one (a) and two (b) phospholipid molecules.

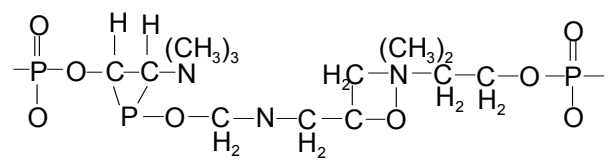

Scheme 3. Scheme of possible complex formation of roundup with two phosphatidylcholine molecules.

liposomal membranes.

\subsection{Lipophilicity}

More detailed elucidation of the mechanism of interaction between the studied substances and the lipid bilayer requires additional investigation. However, it is evident that the formation of complexes of the toxicants with the nonpolar phase of cellular membranes in vivo results in their accumulation inside the membrane. To determine the rate of this process, we determined the concentrations of the substances in octanol and water during a very prolonged time, namely, 18 months.

The octanol/water partition constants $\left(\mathrm{K}_{\mathrm{oct} / \mathrm{H} 2 \mathrm{O}}\right)$, determined $20 \mathrm{~min}$ after mixing of an aqueous solution of the pesticide with octyl alcohol and in 18 months at the end of observation, are presented in Table 3. Sencor and basagran manifest the highest lipophilicity (ability to be dissolved, to a great extent, in the fatty phase octanol).

The process considered in the present work, namely, transfer of the pesticides from water to octanol as the nonpolar phase, was characterized in time by several steps with different transfer rates. The kinetic data of pesticide accumulation in n-octanol are shown in Figure 3. All the compounds considered exhibit pronounced two (and three for some compounds) regions with different rates of the process. During the first $20 \mathrm{~min}$ the relative rate of the concentration change for all compounds is 


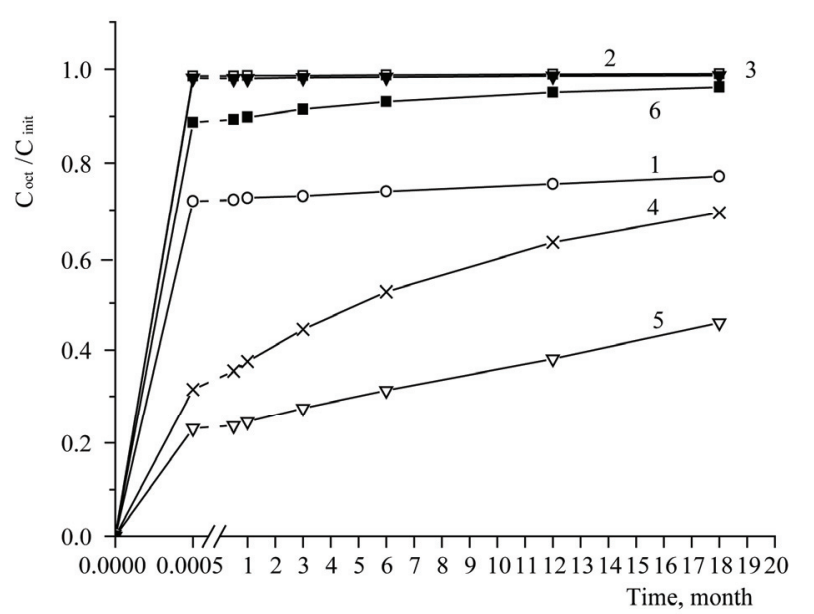

Figure 3. Kinetic curves of pesticide accumulation in octanol. 1 (०) - lontrel; 2 ( $\square)$ - sencor; $3(\nabla)$ - basagran; 4 (X) - roundup; $5(\Delta)$ - kusagard; $6(\square)$ - sethoxydim. a - from 0 to $20 \mathrm{~min} ; \mathrm{b}$ - from $20 \mathrm{~min}$ to 18 months.

maximum: about 98\% sencor and basagran and 90\% sethoxydim transfer from the aqueous phase to n-octanol. In the next time region from 20 min to 6 months, the rate of pesticide transfer from water to the nonpolar phase decreases substantially and the process approaches to saturation. The kinetic curves of sethoxydim and roundup have the third break after 6 months when the diffusion rate decreases once more (more than twofold for roundup).

During one year of measurements, $5 \%$ lontrel are linearly transformed into n-octanol. Up to $25 \%$ kusagard and $30 \%$ roundup are accumulated in the nonpolar phase during 18 months. However, for all the considered compounds, their accumulation in the nonpolar phase does not reach the equilibrium stationary state even after 18 months, and the transfer of the substances from an aqueous solution to octanol evidently continues further.

The transfer rates of the substances to the nonpolar phase in all the three regions are collected in Table 3. According to the accumulation rates of the pesticides in octanol $(\mathrm{V}, \mathrm{mol} / \mathrm{h})$ in the first region $\left(\mathrm{V}_{1}\right)$, all the compounds considered can be arranged in the following order: sencor $>$ lontrel $>$ kusagard $>$ roundup $>$ basargan $>$ sethoxydim.

\subsection{Bioaccumulation}

To model the bioaccumulation process, the measurements of $\mathrm{K}_{\mathrm{oct} / \mathrm{H} 2 \mathrm{O}}$ were repeated in 15 and 30 days, 3, 6, 12 , and 18 months. The ratio of the maximum pesticide concentration in octanol to the initial concentration in an aqueous solution was designed as the bioaccumulation coefficient $(B C)$ :

$$
B C=\left[C_{18 o c t}\right] /\left[C_{\text {init }}\right]
$$

The calculated $\mathrm{BC}$ values are given in Table 3. The minimum $\mathrm{BC}$ value equal to 0.44 was obtained for kusagard, and the maximum $\mathrm{BC}$ value (0.99) was obtained for sencor and basagran. The sequence of the substances by decreasing $\mathrm{BC}$ is as follows: sencor $=$ basagran $>$ sethoxydim $>$ lontrel $>$ roundup $>$ kusagard. This sequence corresponds to the order of these substances by their lipophilicity values (or octanol/water partition constants

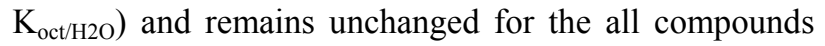
considered during the whole observation period.

The process of toxicant transfer from water to the fatty phase has no upper concentration limit, i.e., does not reach the equilibrium state of the toxicant concentrations in the polar and nonpolar phases but continues to transfer to the nonpolar phase continuously during a very prolonged time (in our specific case, during the whole observation time of 18 months).

Published data are available only for three of the compounds studied by us, namely, basagran, sencor, and roundup. The toxicity values of these substances with respect to various types of multicellular organisms obtained for the "accumulation" parameter are listed in Table 4. First, it is noteworthy that the same toxic dose of basagran is accumulated in organisms of different types: in Crustacea, water insects, animal plankton, or algae. The toxic effect occurs when this compound is accumulated in an amount of $86 \cdot 10^{-6} \mathrm{~g} / 1\left(0.358 \cdot 10^{-6} \mathrm{~mol} / \mathrm{l}\right)$.

Not only one basagran was checked for fishes and algae. As can be seen from the data in Table 4, with respect to algae sencor accumulates the concentration toxic for Chlorella fusca $\left(51 \cdot 10^{-6} \mathrm{~g} / \mathrm{l}, 0.238 \cdot 10^{-6} \mathrm{~mol} / \mathrm{l}\right)$ for $24 \mathrm{~h}$, whereas basagran accumulates its (somewhat higher) toxicity dose for only 30 days. Sencor and roundup were studied for different fish species. Sencor was studied for Leuciscus idus melanotus, and roundup was examined for Cyprinus carpio. Nevertheless, when comparing for one period of action ( 3 days), the accumulated toxic dose of roundup is by 6 (in $\mathrm{g} / \mathrm{ml}$ ) or 10 (in mol/l) times higher than that for sencor. Thus, the toxicity of these three compounds by the "accumulation" parameter generally decreases in the sequence: sencor $>$ basagran $>$ roundup.

The comparison of this series with the data in Table 3 shows that the $\mathrm{K}_{\mathrm{oct} / \mathrm{H} 2 \mathrm{O}}$ values decrease in the same order. Therefore, the above series can hypothetically be extrapolated if assuming that the accumulation value of the studied compounds decreases in the series of decreasing their $\mathrm{K}_{\mathrm{oct} / \mathrm{H} 2 \mathrm{O}}$ : sencor $>$ basagran $>$ sethoxydim $>$ lontrel $>$ roundup $>$ kusagard.

\section{Conclusions}

In our opinion, it is important that the rate of penetration of the metal complexes through the biological membrane is higher than that for the initial pesticide (for instance, 
Table 4. Toxicity doses for basagran, sencor, and roundup accumulated in various organisms.

\begin{tabular}{|c|c|c|c|c|c|c|c|}
\hline \multirow{2}{*}{ Substance } & \multirow{2}{*}{ Common name } & \multirow{2}{*}{ Scientific name } & \multirow{2}{*}{ Living stage } & \multirow{2}{*}{ Time } & \multicolumn{2}{|c|}{ Toxic dose, $10^{-6}$} & \multirow{2}{*}{ Reference } \\
\hline & & & & & $\mathrm{g} / 1$ & $\mathrm{~mol} / \mathrm{l}$ & \\
\hline & & & Crustacea & & & & \\
\hline \multirow[t]{2}{*}{ basagran } & $\underline{\text { Fiddler crab }}$ & Uca minax & not indic. & 11 days & 86 & 0.358 & [19] \\
\hline & & & Water insects & & & & \\
\hline \multirow[t]{2}{*}{ basagran } & $\underline{\text { Southern house mosquito }}$ & Culex quinquefasciatus & not indic. & 30 days & 86 & 0.358 & [19] \\
\hline & \multicolumn{7}{|c|}{ Animal plankton } \\
\hline \multirow[t]{2}{*}{ basagran } & $\underline{\text { Water flea }}$ & Daphnia magna & & 30 days & 86 & 0.358 & [19] \\
\hline & & & Algae & & & & \\
\hline \multirow[t]{2}{*}{ sencor } & $\underline{\text { Green algae }}$ & Chlorella fusca & & $24 \mathrm{~h}$ & 51 & 0.238 & [20] \\
\hline & & Chlorella fusca vacuolata & & $24 \mathrm{~h}$ & 50 & 0.233 & {$[21]$} \\
\hline \multirow[t]{2}{*}{ basagran } & $\underline{\text { Algae, algal mat }}$ & Algae & & 30 days & 86 & 0.358 & [19] \\
\hline & & & Fishes & & & & \\
\hline \multirow[t]{2}{*}{ sencor } & $\underline{\text { Carp }}$ & Leuciscus idus melanotus & $5-6 \mathrm{~cm}, 1.5 \mathrm{~g}$ & 3 days & 54 & 0.225 & [21] \\
\hline & $\underline{\text { Ide, silver or golden orfe }}$ & Leuciscus idus & $2-5 g$ & 3 days & 54 & 0.225 & [20] \\
\hline \multirow[t]{7}{*}{ roundup } & Cyprinus carpio & Cyprinus carpio & $3.5-4.0 \mathrm{~cm}$ & 0.5 day & 531 & 3.14 & [22] \\
\hline & & Cyprinus carpio & $3.5-4.0 \mathrm{~cm}$ & 1 day & 508 & 3.004 & -“"”- \\
\hline & & Cyprinus carpio & $3.5-4.0 \mathrm{~cm}$ & 2 days & 518 & 3.063 & -“"”- \\
\hline & & Cyprinus carpio & $3.5-4.0 \mathrm{~cm}$ & 3 days & 344 & 2.034 & -“"”- \\
\hline & & Cyprinus carpio & $3.5-4.0 \mathrm{~cm}$ & 5 days & 264 & 1.561 & -“"”- \\
\hline & & Cyprinus carpio & $3.5-4.0 \mathrm{~cm}$ & 7 days & 110 & 0.651 & - “"”- \\
\hline & & Cyprinus carpio & $3.5-4.0 \mathrm{~cm}$ & 14 days & 151 & 0.893 & -“"”- \\
\hline
\end{tabular}

lontrel) (Table 2). We have earlier [10,15] found a possibility of easy formation of the lontrel complexes with metals in environmental subjects and their high stability in the non-dissociated form in aqueous solutions. It is also shown that thus formed complexes of various metals are highly reactive as well, and their reactivity is comparable with that of the initial pesticide or even higher $[8,9]$. The data obtained in the present study on the mass transfer rates of the copper and cobalt complexes of the lontrel herbicide revealed that the transfer rate of the com plexes is much higher than that for the initial pesticide: for $\mathrm{Co}(\text { lontrel })_{2}$ by three times, and for $\mathrm{Cu}(\text { lontrel })_{2}$ by almost 10 times. It can be assumed that ecological danger from the toxic action of the studied environmental contaminants increases when they are entrapped into cells in the metal-bound state.

When studying the step of pesticide penetration inside the liposomes, one can assume that fluorescence is quenched due to the escape of $\varepsilon$-ATP from the liposomes.
However, the performed measurements of the concentrations of the copper and cobalt complexes and the presence of residual amounts of $\varepsilon$-ATP inside the liposomes after 20-24 h of measurements prove that all the com pounds considered penetrate through the model liposomal membranes without their complete destruction. The flow of a xenobiotic through the membrane is inde pendent of the initial toxicant concentration and is determined, to a great extent, by its chemical structure. The mass transfer constants of the compounds vary in a wide range from $2 \cdot 10^{-8}$ to $40 \cdot 10^{-8} \mathrm{~mol} \cdot \mathrm{l}^{-1} \mathrm{~s}^{-1}$. The toxicants studied by us can conventionally be classified as 1) highly reactive but with a low membrane permeability (sencor and lontrel), 2) poorly reactive but with a high permeability of the membranes (basagran, sethoxydim), and 3) "resonance," i.e., drastically enhancing their toxicological properties due to the chemical interaction with other environmental contaminants, in particular, with the formation of metal complexes. 


\section{REFERENCES}

[1] A. V. Yablokov, "Poisonous Dressing," Mysl., Moscow, 1990, p. 27. (in Russian)

[2] E. A. Saratovskikh, N. B. Kozlova, V. G. Papin and E. V. Shtamm, "Decomposition of Herbicide Lontrel by Biological and Photochemical Methods," Applied Biochemistry and Microbiology, Vol. 42, No. 1, 2006, pp. 38-44. (in Russian)

[3] V. N. Golubev, "Mechanisms of Interaction of Pesticides with the Lipid Bilayer of Cellular Membranes," Russian Chemical Reviews, Vol. 62, No. 7, 1993, pp. 726-734. (in Russian)

[4] B. T. Bowman and W. W. Sans, "Determination of Octanol-Water Partitioning Coefficient $\left(\mathrm{K}_{\mathrm{ow}}\right)$ of 61 Organophosphorus and Carbamate Insecticides and Their Relationship to Respective Water Solubility (S) Values," Journal of Environmental Science and Health, Vol. B18, No. 6, 1983, pp. 667-683.

[5] H. Miyoshi, T. Nishioka and T. Fujita, "Quantitative Analysis of Effect of Substituted Phenols on Membrane Characteristics of Lecithin Liposomes," Bulletin of the Chemical Society of Japan, Vol. 5, 1986, pp. 1099-1107.

[6] G. Gregoriadis and A. M. Allison (Eds.), "Liposomes in Biological Systems," Meditsina, Moscow, 1983. (in Russian)

[7] Y. Utsuvi, K. Kiyoshige, S. Shimbara and A. Hamada, "Comparative Studies on Cytotoxicity of Micropollutants in Water - Principle of Cytotoxicity Matrix," Journal Seek Entry for Environmental Toxicology and Water Quality, Vol. 9, No. 4, 1994, pp. 333-339.

[8] E. A. Saratovskikh, T. A. Kondrat'eva, B. L. Psikha, R. I. Gvozdev and V. G. Kartsev, "Complex-Formation of Some Pesticides with Adenosine Triphosphoric Acid," The Bulletin of the Russian Academy of the Sciences. Division of Chemical Science, Vol. 37, 1988, pp. 22522258.

[9] E. A. Saratovskikh, M. V. Lichina, B. L. Psikha and R. I. Gvozdev, "Character of the Reaction of Dinucleotides and Polynucleotides with Some Pesticides," The Bulletin of the Russian Academy of the Sciences, Division of Chemical Science, Vol. 38, 1989, pp. 1822-1827.

[10] Z. G. Aliev, L. O. Atovmyan, E. A. Saratovskikh, V. I. Krinichnyi and V. G. Kartsev, "Synthesis, Structure, and Spectral Characteristics of Copper-Complexes with PiColinic-Acid Derivatives," The Bulletin of the Russian Academy of the Sciences. Division of Chemical Science, Vol. 37, 1988, pp. 2246-2252.

[11] Kotyk and K. Yanachek, "Membrane Transport," Mir. Moscow, 1980. (in Russian)

[12] D. A. Frank-Kamenetskii, "Diffusion and Heat Transfer in Chemical Kinetics," Nauka, Moscow, 1987, pp. 103 104. (in Russian)

[13] A. Leo, "Partitioning in Pesticide Mode of Action and Environmental Problems," In: P. S. Magee, G. K. Kohn and J. J. Menn, Eds., Pesticide Synthesis through Rational Approaches, American Chemical Society, Washington, 1984, pp. 213-218.

[14] W. M. Arold, U. Zimmerman, W. Pauli, M. Benzing, C. Niehns and J. Ahlers, "The Comparative Influence of Substituted Phenols (Especially Chlorophenols) on Yeast Cells Assayed by Electro-Rotation and Other Methods," Journal of Biochemica et Biophysica Acta, Vol. 942, No. 1, 1988, pp. 83-95.

[15] E. A. Saratovskikh, "Synthesis of Bidentate Complexes of 3,6-dichloropicolinic Acid," The Bulletin of the Russian Academy of the Sciences. Division of Chemical Science, Vol. 38, 1989, pp. 2140-2141.

[16] M. V. Genkin, B. P. Ulanov, O. E. Dotsenko and R. M. Davydov, "Specific Features of Spectra of Liposome Turbidity," Russian Journal of Physics Chemistry, Vol. 61, No. 1, 1987, pp. 220-224. (in Russian)

[17] T. A. Kondrat'eva, R. I. Gvozdev and L. V. Tat'yanenko, "Spectral Properties of 8-Bromoetheno Derivatives of Adenine Nucleotides," Chemistry of heterocyclic Compounds, No. 7, 1983, pp. 987-992. (in Russian)

[18] J. R. Barrio, J. A. Secrist, N. J. Leonard and G. Weber, "Fluorescent Modification of Adenosine-Containing Coenzymes. Biological Activities and Spectroscopic Properties," Biochemistry, Vol. 19, No. 19, 1972, pp. 3499 3506.

[19] G. M. Booth, C. C. Yu and D. J. Hansen, "Fate, Metabolism, and Toxicity of 3-Isopro-Pyl-1H-2,1,3-BenzoThiadiazin-4(3H)-1-2,2-Dioxide in a Model Ecosystem," Journal of Environmental Quality, Vol. 2, No. 3, 1973, pp. 408-411.

[20] F. Korte, D. Freitag, H. Geyer, W. Klein, A. G. Kraus and E. A. Lahaniatis, "A Concept for Establishing Ecotoxicologic Priority Lists for Chemicals," Chemosphere, Vol. 7, No. 1, 1978, pp. 79-102.

[21] D. Freitag, H. Geyer, A. Kraus, R. Viswanathan, D. Kotzias, A. Attar, W. Klein and F. Korte, "Ecotoxi-Cological Profile Analysis VII. Screening Chemicals for Their Environmental Behavior by Comparative Evaluation," Ecotoxicology and Environmental Safety, Vol. 6, 1982, pp. 60-81.

[22] Y. S. Wang, C. G. Jaw and Y. L. Chen, "Accumulation of 2,4-D and Glyphosate in Fish and Water Hyacinth," $W a$ ter, Air and Soil Pollution, Vol. 74, No. 3-4, 1994, pp. 397-403. 